\title{
Evaluation of Nile tilapia (Oreochromis niloticus) fingerlings exposed to the pesticide pyriproxyfen
}

\author{
Fabio Francisco da Silva ${ }^{1,2}$, Jaqueline Maria da Silva ${ }^{2}$, Themis de Jesus da Silva ${ }^{1}$ \\ Bruno Mendes Tenorio ${ }^{3}$, Fernanda das Chagas Angelo Mendes Tenorio ${ }^{4}$, Elton Lima Santos ${ }^{1}$ \\ Sonia Salgueiro Machado ${ }^{2}$ \& Emerson Carlos Soares ${ }^{1}$ \\ ${ }^{1}$ Aquaculture and Water Quality Laboratory, Agricultural Science Center \\ Federal University of Alagoas, Rio Largo, Alagoas, Brazil \\ ${ }^{2}$ Laboratory of Biotechnology and Enzymology, Institute of Chemistry and Biotechnology \\ Federal University of Alagoas, Maceió, Alagoas, Brazil \\ ${ }^{3}$ Department of Morphology, Health Sciences Center, Federal University of Paraíba \\ João Pessoa, Paraíba, Brazil \\ ${ }^{4}$ Department of Histology and Embryology, Bioscience Center, Federal University of Pernambuco \\ Recife, Pernambuco, Brazil \\ Corresponding author: Emerson Carlos Soares (soaemerson@gmail.com)
}

\begin{abstract}
Oreochromis niloticus (Nile tilapia) is one of the most produced fish for human consumption globally; however, these fish are susceptible to exposure to toxic chemicals in the water. Pyriproxyfen is a pesticide widely used to control mosquitoes in drinking water supplies and pests in crops. The present study aimed to examine pyriproxyfen's effects on fish $O$. niloticus fingerlings exposed using an acute $96 \mathrm{~h}$ and subchronic tests for 28 days. The lethal concentration $\mathrm{LC}_{50}-96 \mathrm{~h}$ for $O$. niloticus was $2.77 \mathrm{mg} \mathrm{L}^{-1}$, no observed effect concentration (NOEC), and the lowest observed effect concentration (LOEC) was 1.0 and $2.5 \mathrm{mg} \mathrm{L}^{-1}$, respectively. The hepatic catalase activity was significantly changed after exposure to pyriproxyfen above 0.4 $\mathrm{mg} \mathrm{L}^{-1}$. Pyriproxyfen also induced histopathological lesions in the hepatic tissue at 28 days in a dose-dependent pattern at concentrations above $0.4 \mathrm{mg} \mathrm{L}^{-1}$. Pyriproxyfen above $1.2 \mathrm{mg} \mathrm{L}^{-1}$ reduced the locomotor behavior, distance traveled inside the tank, mean speed, and angular variation. This pesticide also decreased weight gain, food conversion, and specific growth rate at concentrations above $1.2 \mathrm{mg} \mathrm{L}^{-1}$. In conclusion, exposure to pyriproxyfen in water from $0.4 \mathrm{mg} \mathrm{L}^{-1}$ may impair $O$. niloticus development; consequently, pyriproxyfen may affect this fish's production and quality at higher concentrations than commonly used in water $\left(0.01 \mathrm{mg} \mathrm{L}^{-1}\right)$.
\end{abstract}

Keywords: Oreochromis niloticus; fish; pyriproxyfen; $\mathrm{LC}_{50}$; locomotor behavior; catalase; histopathology

\section{INTRODUCTION}

The worldwide use and adverse consequences attributed to pesticides have increased in the last few decades (La Verda et al., 2015; Legrand et al., 2017). Also, the indiscriminate use of pesticides has risen in tropical areas due to the epidemic of dengue, chikungunya, and zika, mainly due to the climate and inappropriate sanitary conditions (Marcondes \& Ximenes, 2016).

The widespread dispersion of Aedes aegypti and effective adaptation to urban areas enhanced the need for more efficient pesticides, among this pyriproxyfen (4-phenoxy phenyl (RS)-2-(2-pyridyloxy) propyl ether).
Pyriproxyfen is a pyridine-based larvicide used directly in water supplies to control the proliferation of mosquito larvae (Caixeta et al., 2016; Dzieciolowska et al., 2017; Peterson et al., 2017; Maharajan et al., 2018). This larvicide is an analog of a juvenile hormone that acts to inhibit the mosquito's metamorphosis and embryogenesis (Ohba et al., 2013). Previously investigators reported adverse effects following exposure to low concentrations of pyriproxyfen (Truong et al., 2016; Dzieciolowska et al., 2017). Due to low solubility, high partition coefficients, and hydrophobicity of pyriproxyfen, this pesticide displays the potential to be environmentally persistent, and precautions need to be taken when applying pyriproxyfen to or near water

Corresponding editor: Fernando Vega 
bodies in order to avoid contamination of water. When exposed to natural light in river water, the half-live of 21 days was observed for pyriproxyfen, more stable in dark conditions (Sullivan \& Goh, 2008). Besides, pyriproxyfen was used as a pesticide in households for California red scale, silver leaf whitefly, and red fire ant in citrus, cotton, vegetable, and peanut crops (Legrand et al., 2017; Maharajan et al., 2018). Pesticides applied to crops may inadvertently reach aquatic ecosystems and accumulate in sediment and living organisms such as fish (Tenorio et al., 2017). The guideline value for daily intake of pyriproxyfen is $100 \mathrm{mg} \mathrm{kg}^{-1}$ of bodyweight per day for a lifetime, and the recommended use of pyriproxyfen in the drinking water sources is 0.01 $\mathrm{mg} \mathrm{L} \mathrm{L}^{-1}$, the dose also used to control mosquito $A$. aegypti (Caixeta et al., 2016; Maharajan et al., 2018). Due to its very low mammalian toxicity, pyriproxyfen is approved by the World Health Organization (WHO) to treat potable water against mosquitoes. However, studies have observed increased mosquitoes resistance to the pesticide pyriproxyfen (Maoz et al., 2017).

Oreochromis niloticus (Nile tilapia) is produced in more than 140 countries; it is very versatile in fish farming (Meurer et al., 2005; Vieira et al., 2018) and is the second most widely cultivated fish group globally. Its production occurs mainly in net-tanks in dammed water bodies (Furuya et al., 2004; FAO, 2010). Tilapia production has quadrupled over the past decade because of its suitability for aquaculture, marketability, and stable market prices. Tilapia continued its rapid increase in global production with 5,576,800 mt, clearly emerged as a very promising group in aquaculture (Prabu et al., 2019).

Since pyriproxyfen exhibits the potential to be environmentally persistent in water, this study's objective was to determine the $50 \%$ lethal concentration $\left(\mathrm{LC}_{50}\right)$, NOEC, LOEC, and catalase activity $96 \mathrm{~h}$ after exposure of $O$. niloticus to a commercial formulation of pyriproxyfen. These commercial formulations have been recommended to be used in water supplies to control mosquitoes' proliferation in the country. This study, based upon $\mathrm{LC}_{50}$ value, also determined the effects of these concentrations of pyriproxyfen formulations on biometric performance, hepatic microstructure, and locomotor behavior of fish under subchronic toxicity tests for 28 days.

\section{MATERIALS AND METHODS}

Experimental methodologies were approved by the Ethics Commission on the Use of Animals of the Federal University of Alagoas (protocol no. 57/2016), in accordance with the principles for research using animals.

\section{Reagents}

All chemicals, including 5,5-dithio-bis-nitrobenzoic acid (DTNB; 98\%), acetylthiocholine iodide (ASCh; 97\%), bovine serum albumin (BSA; 98\%), sodium chloride, were purchased from Sigma - Aldrich (St. Louis, MO, USA). Pyriproxyfen was obtained from commercial formulation Sumitomo Tiger100EC (Japan).

\section{Oreochromis niloticus and fish acclimatization}

Fish fingerlings were produced and supplied from the pisciculture station of the Agriculture Science Center of the Federal University of Alagoas - CECA/UFAL. Before initial biometry, fingerlings of $O$. niloticus were acclimated to lab conditions in $240 \mathrm{~L}$ tanks containing dechlorinated water with air recycling system aerator, a biological filter containing oysters, bio-balls, porcelain, PVC screens, bacteria placed exogenously, and UV filter (Jebo, China) for ten days at room temperature (26 $\pm 1^{\circ} \mathrm{C}$ ) under a $12 \mathrm{~h}$ photoperiod, and then transferred to the experimental tanks $(20 \mathrm{~L})$. During all experimental periods, water quality parameters were monitored by a multiparameter probe (HANNA Instruments, model 9828, Woonsocket, USA). Temperature was $24.3 \pm 0.1^{\circ} \mathrm{C} ; \mathrm{pH} 7.1 \pm 0.2$; dissolved oxygen $6.5 \pm$ $0.2 \mathrm{mg} \mathrm{L}^{-1}$; total ammonia-nitrogen $<0.01 \mathrm{mg} \mathrm{L}^{-1}$; total dissolved solids $\left(542 \pm 21 \mathrm{mg} \mathrm{L}^{-1}\right)$; conductivity $(863 \pm$ $\left.63 \Omega \mathrm{m}^{-1}\right)$. According to the manufacturer's specification, fish were fed three times per day with extruded commercial feed ( $3 \mathrm{~mm})$, containing $45 \%$ (minimum) crude protein.

\section{Acute toxicity assay $(96 \mathrm{~h})$}

Fish were submitted to biometry (mean weight $3.5 \pm 0.5$ $\mathrm{g}$; mean length $4.5 \pm 0.5 \mathrm{~cm}$ ), and then assigned to control or groups exposed to different concentrations of pyriproxyfen for $96 \mathrm{~h}$. O. niloticus fingerlings were distributed into nine groups of 10 animals each according to the exposure concentration of pyriproxyfen $(0.0$ (control); $0.25,0.5,1,2.5,3,4,5$ or $10 \mathrm{mg}$ $\left.\mathrm{L}^{-1}\right)$. Pyriproxyfen stock solutions were prepared (100 $\mathrm{g} \mathrm{L}^{-1}$ ) and diluted appropriately to reach each treatment's concentrations. Each assay was replicated three times, and fish remained unfed during the assay period.

The number of deaths in each treatment was recorded at $24 \mathrm{~h}$ intervals. If the death occurred, it was noted, and fish were immediately removed from the experimental tanks. After $96 \mathrm{~h}$, the number of dead fish in each group was recorded, and the $96 \mathrm{~h}-\mathrm{LC}_{50}$ values (with $95 \%$ confidence intervals; 95\% CI) for pyriproxyfen were calculated based on cumulative mortality data using the GraphPad 5.0 prism (Graph Pad Software Inc., San Diego, CA, USA) and Probit model, according to Silva et al. (2015). The lack of 
movement and no response to tactile stimuli were used to verify mortality. Non-observed effect concentration (NOEC) and the lowest observed effect concentration (LOEC) were computed with an R-script from mix to 1.3.2 with a significance level of 0.01 (Zhu et al., 2016).

\section{Subchronic toxicity tests (28 days)}

Fish were submitted to biometry (mean weight $3.5 \pm 0.5$ $\mathrm{g}$; mean length $4.5 \pm 0.5 \mathrm{~cm}$ ). O. niloticus fingerlings were exposed to pyriproxyfen concentrations 0.0 (control), 0.4, 0.8, 1.2 and $1.8 \mathrm{mg} \mathrm{L}^{-1}$ with three replicas each for 28 days $(n=6)$. The range of concentrations tested was selected to be below the $96 \mathrm{~h}-\mathrm{LC}_{50}$ values obtained in the acute toxicity test described above (highest concentration is around $65 \%$ of the $\mathrm{LC}_{50}$ ).

During the subchronic toxicity test, animals were fed three times a day (08:00, 12:00 and 16:00 h) ad libitum. The experimental tanks were maintained under constant aeration, siphoned daily with water, and pyriproxyfen replacement (20\%). The water quality, temperature, dissolved oxygen, and $\mathrm{pH}$ indicators were monitored daily at 8:00 and 16:00 h, using a multiparameter probe (Hanna Instruments, model 9828, Woonsocket, USA). Total ammonia $\left(\mathrm{mg} \mathrm{L}^{-1}\right)$ was weekly measured spectrophotometrically at $450 \mathrm{~nm}$ (spectrophotometer Hanna Instruments, model HI 83203, Belgium).

After experimental treatment, animals were anesthetized with $150 \mathrm{mg} \mathrm{L}^{-1}$ Tricaine MS222, producing unconsciousness to be sacrificed by cranial perfusion. Tissues were removed and stored for later lab analysis (Silva et al., 2015; Chaves et al., 2017).

\section{Liver extract preparation and catalase activity}

Crude liver extracts from animals exposed to the subchronic toxicity tests were prepared using a liver from a pool of three animals for each tested concentration. Liver tissues were suspended in a 20 $\mathrm{mM}$ potassium phosphate buffer $(\mathrm{pH} 7.4,0.1 \%$ Triton $\mathrm{X}-100$ and $150 \mathrm{mM} \mathrm{NaCl}, 1: 20$ dilution) and further homogenized with a Potter-Elvejhem glass homogenizer. Catalase activity in the liver extract was assayed spectrophotometrically at $240 \mathrm{~nm}$ using hydrogen peroxide $\left(\mathrm{H}_{2} \mathrm{O}_{2}\right)$ as a substrate (Moraes et al., 2007). One-Unit (U) of CAT activity was calculated in terms of $\mu \mathrm{mol} \mathrm{H}_{2} \mathrm{O}_{2}$ consumed $\mathrm{min}^{-1}$.

\section{Evaluation of the fish biometric performance}

The parameters examined included: 1) total length (cm) (TL); 2) daily weight gain (g) (DWG): mean final weight minus the initial mean weight divided by the number of days; 3 ) apparent feed conversion (AFC): the total amount of dry feed supplied to the fish divided by the total weight gain (mean final weight minus mean initial weight); 4) specific growth rate (SGR): SGR = $100 \times$ (ln final weight / ln initial weight) / experiment time.

\section{Locomotion behavior analysis}

Control and treated fish were filmed after 28 days using a digital camera Finepix 4500 (Fujifilm, Brazil) positioned $30 \mathrm{~cm}$ from experimental tanks. The locomotor behavior was assessed as described by Tenorio et al. (2017). Briefly, the videos were recorded at $320 \times 240$ pixels and 30 frames per second (FPS) for $10 \mathrm{~min}$. This video resolution was sufficient to track the fish. After, the videos were transformed into 4 FPS using Virtual Dub 1.10.4 software (Avery Lee); therefore, four images per sec were employed to analyze locomotor behavior, using a total of 2,400 points of coordinate $\mathrm{X}, \mathrm{Y}$, which described the locomotor behavior of each fish. The video tracking was performed using the software Image $\mathrm{J} 1.49 \mathrm{v}$ (National Institutes of Health-NIH, USA) with the plug-in MTrackJ (Meijering et al., 2012; Erasmus University Medical Center, Netherlands), obtaining the following parameters: 1) traveled distance $(\mathrm{cm})$ : quantify the length of fish trajectory in the tank, starting from the first coordinate point of the trajectory to its last point, 2) D2S (cm): average distance from the first coordinate point to the current point, 3) D2P $(\mathrm{cm})$ : mean distance from the current coordinate point to the previous point, 4) $\theta$ (degrees): angle of the in-plane components of the track points vector, 5) $\Delta \theta$ (degrees): angular change between the in-plane components of the track points vector, 6) mean speed $\left(\mathrm{cm} \mathrm{s}^{-1}\right)$ : traveled distance per time.

\section{Histopathological analysis of the liver}

The fish liver was removed, dissected, and weighed. Fragments of hepatic tissue with $3 \mathrm{~mm}$ thickness were cut and then immersed in formalin solution in phosphate buffer (10\%) for $24 \mathrm{~h}$. Subsequently, the fragments were immersed in $70 \%$ alcohol and stored. After fixation, liver samples were dehydrated by increasing ethanol concentrations to absolute ethanol, diaphanized in xylol, infiltrated, and embedded in paraffin. The obtained blocks were cut utilizing a microtome to obtain $4 \mu \mathrm{m}$ cross-sections and stained with hematoxylin-eosin. The histological sections were photographed with an optical microscope (Diagtech, Brazil) attached to a camera (Motic 2300, Hong Kong) connected to a computer and analyzed using the biometric software Motic Images Plus 2.0 (Hong Kong). The microscopic descriptions of $O$. niloticus liver structure were performed as described by Vicentini et al. (2005). 


\section{Statistical analyses}

The homogeneity of the animals was confirmed by the Cochran test $(P<0.05)$. The results obtained in this study were evaluated using the software Systat 13.0, SPSS package, utilizing analysis of variance (ANOVA), and Tukey's tests for parametric data in with a full random experimental design, as well as the Kruskal-Wallis and Dunn tests for non-parametric data. Results were expressed as mean \pm standard deviation. A $P$-value $<0.05$ was considered statistically significant.

\section{RESULTS}

The water quality parameters measured during the ten days acclimation period, acute toxicity assay (96 h), and subchronic toxicity tests (28 days) did not show significant changes (temperature $24.3 \pm 0.1^{\circ} \mathrm{C} ; \mathrm{pH} 7.1$ \pm 0.2 ; and dissolved oxygen $6.5 \pm 0.2 \mathrm{mg} \mathrm{L}^{-1}$ ).

\section{Acute toxicity assay $(96 \mathrm{~h})$}

After $96 \mathrm{~h}$ exposure to pyriproxyfen, the fish mortality observations occurred between concentrations 2.5 to 10 $\mathrm{mg} \mathrm{L}^{-1}$ (Fig. 1). A $100 \%$ mortality rate occurred after exposure above $4 \mathrm{mg} \mathrm{L}^{-1}$ pyriproxyfen. The $96 \mathrm{~h}-\mathrm{LC}_{50}$ value of pyriproxyfen was $2.77 \mathrm{mg} \mathrm{L}^{-1}$, the $95 \%$ confidence interval was 1.381 to 1.412 (Fig. 1). Data also demonstrated the influence of exposure time on mortality frequency. The longer the exposure time, the higher the rate of fish mortality. The no observed effect concentration (NOEC) and the lowest observed effect concentration (LOEC) for Oreochromis niloticus fish exposed to pyriproxyfen were 1 and $2.5 \mathrm{mg} \mathrm{L}^{-1}$, respectively.

\section{Catalase (CAT) activity}

Compared to the control, the hepatic CAT showed significant change after exposure to each concentration of pesticide pyriproxyfen tested in the subchronic experiment (Fig. 2).

\section{Subchronic toxicity tests (28 days)}

Since exposure concentrations used in this experiment were below the $\mathrm{LC}_{50}$ for pyriproxyfen, no mortality was observed in the control group during the experimental period.

\section{Evaluation of the fish biometric performance}

Values of the zootechnical parameters: total length (TL), daily weight gain (DWG), specific growth rate (SGR), and apparent feed conversion (AFC), increased after exposure to pyriproxyfen above $1.2 \mathrm{mg} \mathrm{L}^{-1}$ (Table $1)$.

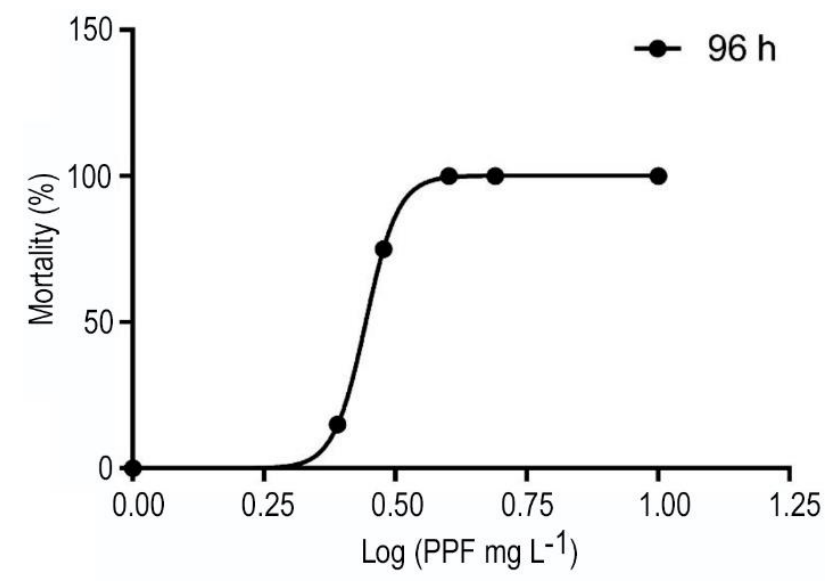

Figure 1. Percentage of mortality of Oreochromis niloticus fingerlings exposed to different concentrations of pyriproxyfen (PPF) for 96 hours.

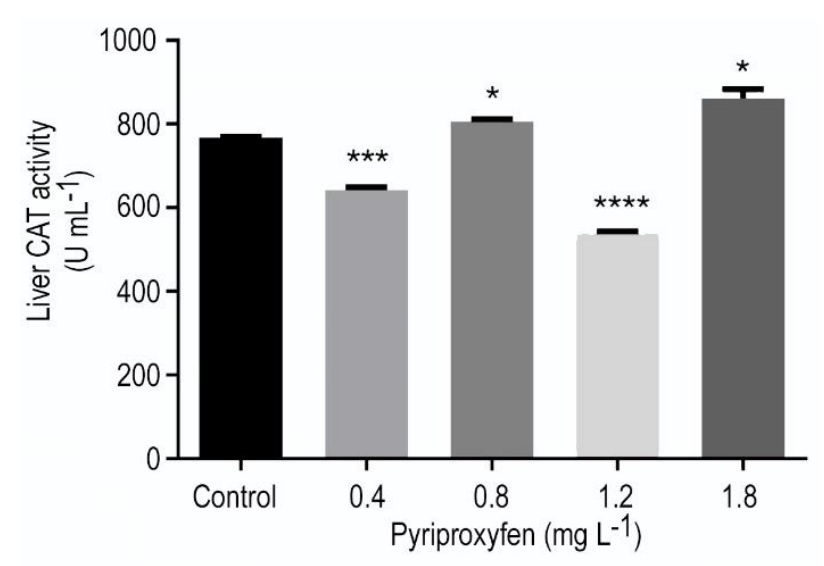

Figure 2. Catalase (CAT) activity in the liver of Oreochromis niloticus fingerlings exposed to different concentrations $\left(\mathrm{mg} \mathrm{L}^{-1}\right)$ of pyriproxyfen (PPF) for 96 hours. *Indicates a statistically significant difference.

\section{Locomotion behavior analysis}

Fish exposed to pyriproxyfen above $1.2 \mathrm{mg} \mathrm{L}^{-1}$ for 28 days exhibited a reduction in the traveled distance inside the tank, mean speed, path parameter D2P, as well as the parameter angular variation of the trajectory (Table 2). Limitations in the video tracking of fish exposed to $1.8 \mathrm{mg} \mathrm{L}^{-1}$ pyriproxyfen did not allow an adequate quantitative analysis. Fish crowded, making individual locomotor behavior analysis unviable in these fish.

\section{Histopathological analysis of the fish liver}

The liver of control fish showed normal structure for the $O$. niloticus (Fig. 3). The hepatocytes displayed cordonal distribution forming plaques. The hepatocytes were rounded with normal size; nuclei were spherical and central with a prominent nucleolus. The cytoplasm was clear and rich in lipids removed by histological 
Table 1. Biometric performance of Oreochromis niloticus fingerlings exposed to pyriproxyfen concentrations $0.4,0.8,1.2$, and $1.8 \mathrm{mg} \mathrm{L}^{-1}$. TL: total length, DWG: daily weight gain, AFC: apparent feed conversion, SGR: specific growth rate, after exposure to pyriproxyfen, mean \pm standard deviation, CV: coefficient of variation. Different superscript letters in the same line indicate a statistically significant difference $(P<0.05)$.

\begin{tabular}{|c|c|c|c|c|c|c|}
\hline Variables & Control & $0.4 \mathrm{mg} \mathrm{L}^{-1}$ & $0.8 \mathrm{mg} \mathrm{L}^{-1}$ & $1.2 \mathrm{mg} \mathrm{L}^{-1}$ & $1.8 \mathrm{mg} \mathrm{L}^{-1}$ & CV\% \\
\hline TL & $7.27 \pm 0.24^{\mathrm{a}}$ & $7.55 \pm 0.44^{\mathrm{a}}$ & $7.33 \pm 0.52^{\mathrm{a}}$ & $6.74 \pm 0.21^{\mathrm{ab}}$ & $5.88 \pm 0.49^{b}$ & 5.2 \\
\hline DWG & $6.80 \pm 0.81^{\mathrm{a}}$ & $7.40 \pm 1.30^{\mathrm{a}}$ & $6.84 \pm 1.19^{\mathrm{a}}$ & $5.30 \pm 1.25^{\mathrm{a}}$ & $3.52 \pm 0.94^{\mathrm{b}}$ & 24.6 \\
\hline AFC & $1.20 \pm 0.32^{\mathrm{a}}$ & $1.36 \pm 0.3^{\mathrm{a}}$ & $1.22 \pm 0.29^{\mathrm{a}}$ & $1.47 \pm 0.38^{\mathrm{b}}$ & $5.17 \pm 0.42^{\mathrm{c}}$ & 17.1 \\
\hline SGR & $1.26 \pm 0.2^{\mathrm{a}}$ & $1.39 \pm 0.19^{\mathrm{a}}$ & $1.26 \pm 0.14^{\mathrm{a}}$ & $0.86 \pm 0.1^{\mathrm{b}}$ & $0.24 \pm 0.03^{b}$ & 12.6 \\
\hline
\end{tabular}

Table 2. Locomotor behavior of Oreochromis niloticus exposed to pyriproxyfen 0.8 and $1.2 \mathrm{mg} \mathrm{L}^{-1}$ for 28 days. Distance $(\mathrm{cm}), \mathrm{D} 2 \mathrm{~S}(\mathrm{~cm}), \mathrm{D} 2 \mathrm{P}(\mathrm{cm}), \theta$ (degrees), $\Delta \theta$ (degrees), and mean speed $\left(\mathrm{cm} \mathrm{s}^{-1}\right)$. Mean \pm standard deviation. Different superscript letters in the same column indicate a statistically significant difference $(P<0.05)$.

\begin{tabular}{lcccrcc}
\hline & Distance & D2S & D2P & $\theta$ & $\Delta \theta$ & Speed \\
\hline Control & $4164.8 \pm 991.0^{\mathrm{a}}$ & $11.5 \pm 4.2$ & $1.7 \pm 0.4^{\mathrm{a}}$ & $1.0 \pm 2.8$ & $-1.0 \pm 1.4^{\mathrm{a}}$ & $6.9 \pm 1.6^{\mathrm{a}}$ \\
$0.8 \mathrm{mg} \mathrm{L}^{-1}$ & $3369.0 \pm 593.1^{\mathrm{ab}}$ & $15.5 \pm 2.4$ & $1.4 \pm 0.2^{\mathrm{ab}}$ & $-0.8 \pm 1.8$ & $0.5 \pm 1.1^{\mathrm{ab}}$ & $5.6 \pm 0.9^{\mathrm{ab}}$ \\
$1.2 \mathrm{mg} \mathrm{L}^{-1}$ & $2785.8 \pm 721.5^{\mathrm{b}}$ & $15.9 \pm 7.6$ & $1.1 \pm 0.3^{\mathrm{b}}$ & $1.4 \pm 4.0$ & $1.2 \pm 0.7^{\mathrm{b}}$ & $4.6 \pm 1.2^{\mathrm{b}}$ \\
\hline
\end{tabular}

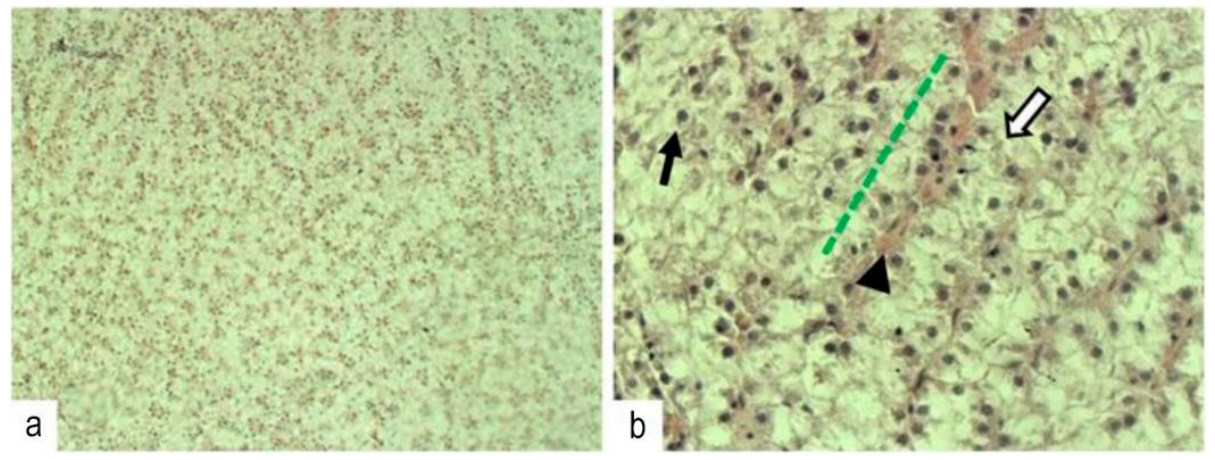

Figure 3. Photomicrographs of the liver in Oreochromis niloticus fingerlings (control group). a) Liver tissue without histopathological changes (100x), b) cordonal arrangement of hepatocytes (green trace), spherical and centralized nucleus (arrow); hepatic sinusoid capillary (arrowhead) and organization in a double strand of hepatocytes between the sinusoids (large white arrow) (400x).

processing, showing a light background (negative staining). The central vein appeared normal with small sinusoidal capillaries in direct contact with hepatocytes. These sinusoids were abundant, lined by normal endothelial cells, and filled with erythrocytes showing eosinophilic staining. The liver also contained exocrine pancreatic tissue, with an acinar organization, light brown granules, and diffuse localizations.

The fish $O$. niloticus exposed to $0.4 \mathrm{mg} \mathrm{L}^{-1}$ pyriproxyfen exhibited some morphological alterations in the liver (Figs. 4a-b), areas with loss of the hepatocytes' cordial organization, with nucleus displaced to the periphery, the cytoplasm was more stained and less vacuolated. The liver also showed small areas of inflammatory infiltrate and sinusoidal capillaries with mild congestion.
Exposure to $0.8 \mathrm{mg} \mathrm{L}^{-1}$ pyriproxyfen (Figs. $4 \mathrm{c}-\mathrm{d}$ ) induced loss of hepatocytes' cordonal organization in several areas, with a peripheral nucleus and greater vacuolization. The hepatic parenchyma contained increased multifocal congestion of the sinusoids and an increased amount of immune cells. Areas of inflammatory infiltration and fibrosis in hepatic tissue were also observed. Exposure to a concentration of $1.2 \mathrm{mg} \mathrm{L}^{-1}$ pyriproxyfen induced even more severe pathological lesions, wide areas of vacuolization in the hepatocytes, and greater congestion in the sinusoidal capillaries. Many hepatocytes also exhibited nucleus displaced to cellular periphery and loss of cordonal arrangement. Several dispersed immune cells were detected among hepatocytes and sinusoids, and several inflammatories infiltrate and areas of fibrosis (Figs. 4e-f). 


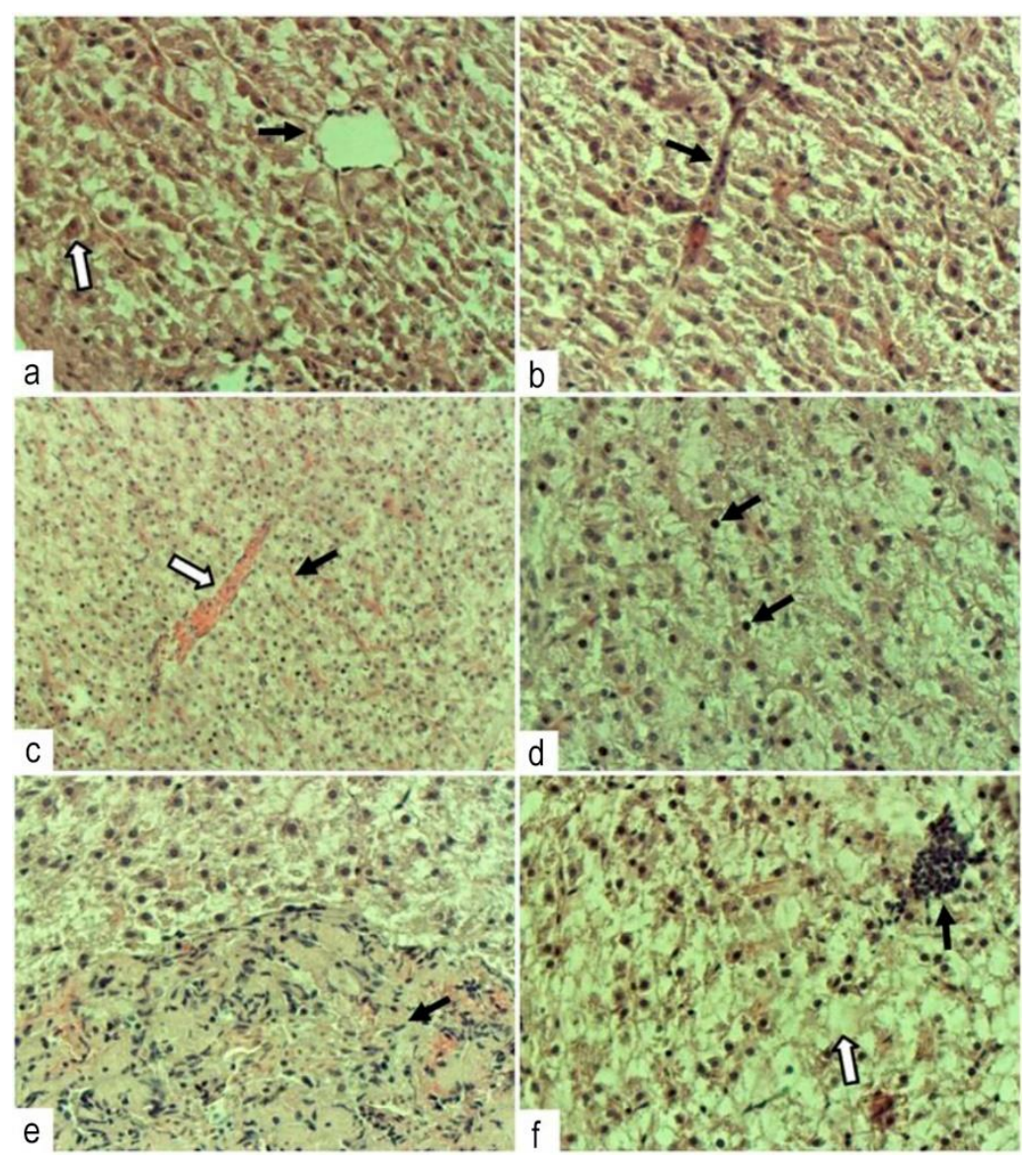

Figure 4. Photomicrographs of the liver in Oreochromis niloticus fingerlings exposed to pyriproxyfen concentrations: a-b) $0.4 \mathrm{mg} \mathrm{L}^{-1}$, c-d) $0.8 \mathrm{mg} \mathrm{L}^{-1}$, e-f) $1.2 \mathrm{mg} \mathrm{L}^{-1}$ for 28 days. a) Liver tissue showing the central vein (black arrow) and hepatocyte with nucleus displaced to the periphery (white arrow), 400x; b) note congestion of the blood vessel (black arrow), 400x; c) central vein in longitudinal section (white arrow) from which the sinusoidal capillaries proceed in radial pattern (arrow), 200x; d) liver tissue showing the greater presence of immune cells (black arrow), 400x; e) areas of fibrosis in the liver (black arrow), 400x; f) inflammatory infiltrate in the hepatic tissue (black arrow) and wide areas of vacuolization (white arrow), 400x.

\section{DISCUSSION}

Many chemicals are released continuously into the environment, including endocrine disruptors, heavy metals, oils, personal care products, pharmaceuticals, and pesticides. Pyriproxyfen is a pesticide widely used in tropical areas to control the proliferation of mosquitos larvae in aquatic habitats; besides, it is used as a pesticide in citrus, cotton, vegetable, and peanut crops; this pesticide can be carried by rain to aquatic environments, exposing non-target species like fish to this pesticide (Caixeta et al., 2016; Legrand et al., 2017; Peterson et al., 2017; Tenorio et al., 2017).

Studies report concerns about pyriproxyfen inducing adverse effects in aquatic ecosystems at concentrations required to control mosquitos' larvae (Caixeta et al., 2016). Toxicity tests for pyriprox yfen at different concentrations using Daphnia magna and
Artemia salina showed high toxicity in both microcrustaceans; the lowest-observed-effect concentration of pyriproxyfen was $1.25 \mu \mathrm{g} \mathrm{L}^{-1}$ (Santos et al., 2017). Pyriproxyfen's toxicity was also investigated in estuarine copepods Eurytemora affinis, illustrating 48 and $96 \mathrm{~h}-\mathrm{LC}_{50}$ of 73.24 and $29.70 \mu \mathrm{g} \mathrm{L} \mathrm{L}^{-1}$, respectively (Legrand et al., 2017).

Pyriproxyfen exhibits low solubility, high partition coefficients, and hydrophobicity; therefore, this pesticide is consistent with chemical characteristics that are environmentally persistent (Sullivan \& Goh, 2008). When comparing the pyriproxyfen $\mathrm{LC}_{50}$ for larvivorous fish Pseudomugil signifier (0.84 $\mathrm{mg} \mathrm{L}^{-1}$ ) (Brown et al., 1998), bluegill sunfish Lepomis macrochirus $(0.27 \mathrm{mg}$ $\left.\mathrm{L}^{-1}\right)$, and rainbow trout Oncorhynchus mykiss $(0.33 \mathrm{mg}$ $\mathrm{L}^{-1}$ ) (WHO, 2006); in the present study, the Oreochromis niloticus fingerlings $\mathrm{LC}_{50}$ at $2.77 \mathrm{mg} \mathrm{L}^{-1}$ was higher indicating greater resistance to this pesticide. In 
agreement with this observation, FAO (2010) noted that $O$. niloticus fish were known to be resistant to various adverse conditions such as poor water quality and disease.

Pyriproxyfen $1.2 \mathrm{mg} \mathrm{L}^{-1}$ altered the locomotor behavior of fish $O$. niloticus. These findings are novel as no apparent studies were found examining behavioral changes in $O$. niloticus after exposure to the pesticide pyriproxyfen. Also, O. niloticus seem to be more resistant to behavioral changes produced by this pesticide since Xiphophorus maculatus fish exposed to pyriproxyfen concentration close to the dosage used to control mosquito A. aegypti $\left(10 \mu \mathrm{g} \mathrm{L}^{-1}\right)$ did not markedly affect the rate of mortality. However, this concentration may decrease the swimming performance, as evidenced by erratic swimming and loss of equilibrium (Caixeta et al., 2016). Truong et al. (2016) demonstrated adverse behavioral effects in embryonic zebrafish Danio rerio exposed to pyriproxyfen $6.4 \mu \mathrm{M}$. They raised concerns as locomotor behavior changes impair feeding ability, reproduction, and survival in aquatic environments (Tenorio et al., 2017). Behavioral responses were used to assess toxicological changes in aquatic animals (Peterson et al., 2017), including fish (Renick et al., 2016). Therefore, toxicity tests using behavioral changes may represent a reliable tool to detect toxicity attributed to contaminants in animals and aquatic organisms (García de la Parra et al., 2006; Tenorio et al., 2017).

Recent studies showed that pyriproxyfen did not induce developmental abnormalities in zebrafish embryo at concentrations equivalent to levels used in mosquitoes control practice; however, doses higher than $1.0 \mathrm{mg} \mathrm{L}^{-1}$ induced marked teratogenic effect on zebrafish embryos (Dzieciolowska et al., 2017). The concentration of pyriproxyfen, resulting in $50 \%$ of zebrafish presenting adverse morphological effects, was $5.2 \mu \mathrm{M}$ (Truong et al., 2016).

Catalase is a key enzyme that plays an essential role in cell defense agains $t$ oxidative stress. Several investigators noted changes in liver CAT activity in fish exposed to pesticides, and thus considered this enzyme a useful marker of chemical-mediated tissue oxidation (Moraes et al., 2007; Clasen et al., 2018). Catalase activity is higher in organs with high oxidative potential such as the liver, kidney, and erythrocytes (Glorieux et al., 2015). Several studies have shown changes in liver catalase of fish exposed to pesticides, and catalase has been considered a useful marker of liver changes due to damage by toxic substances (Moraes et al., 2007; Clasen et al., 2018).

Although no clear pattern was observed, the present study showed changes in CAT activity in the liver of fish $O$. niloticus exposed to commercial formulation of pyriproxyfen decreasing at 0.4 and $1.2 \mathrm{mg} \mathrm{L}^{-1}$ and increasing at 0.8 and $1.8 \mathrm{mg} \mathrm{L}^{-1}$, suggesting a role for catalase in the defense mechanism to reduce oxidative stress that needs to be better understood. Other studies also showed variation in liver CAT activity of $O$. niloticus exposed to pesticides, such as methomyl (Meng et al., 2014). A decrease in CAT activity indicates a reduced capacity to scavenge hydrogen peroxide produced in the liver, and this inhibition caused by pesticide was reported in several fish species (Ural, 2013). In the present study, the variation found in catalase activity after exposure to pyriproxyfen showed a pattern similar to that observed previously in the catalase of fish Catla catla after exposure to the pesticide methyl parathion (Abhijith et al., 2016). Moreover, zebrafish embryo exposed to $1.66 \mu \mathrm{g} \mathrm{mL}^{-1}$ pyriproxyfen showed increased catalase activity (Maharajan et al., 2018).

The biphasic liver CAT response, together with the histopathological tissue changes, indicates oxidative stress in the liver of fish $O$. niloticus after exposure to pyriproxyfen at the lowest dose employed $0.4 \mathrm{mg} \mathrm{L}^{-1}$. It is worth noting that in our study, changes were observed in fish at doses of pyriproxyfen close to that used directly in water reservoirs to control mosquitoes proliferation $\left(10 \mu \mathrm{g} \mathrm{L}^{-1}\right)$, especially when one considers the persistence of the pesticide in the environment and the tendency to bioconcentrate (Ose et al., 2017) in the animal organism several-fold higher than that found in the water where these animals live (Caixeta et al., 2016; Tenorio et al., 2017).

The present study also demonstrated changes in the liver microstructure of $O$. niloticus exposed to pyriproxyfen, including an increase of inflammatory infiltrate, fibrosis, elevated amount of immune cells, vacuolization in the hepatocytes, and congestion in the sinusoidal capillaries. These hepatic histopathological alterations in the liver increased in a dose-dependent pattern. Few reports examined the effects of pyriproxyfen on the microstructure of fish organs. Maharajan et al. (2018) found that histopathological analysis of zebrafish following exposure to pyriproxyfen $1.66 \mu \mathrm{g} \mathrm{mL}^{-1}$ resulted in thinning of heart muscles, pericardial edema, and hyperemia. However, no apparent data on pyriproxyfen's influence on liver microstructure in fish $O$. niloticus was available. Corroborating, pyriproxyfen metabolites are widely distributed in the liver after exposure to this pesticide (Ose et al., 2017).

\section{CONCLUSIONS}

Exposure to the pesticide pyriproxyfen at concentrations above $1.2 \mathrm{mg} \mathrm{L}^{-1}$ impaired growth and behavior 
of fish Oreochromis niloticus and damaged the liver. These parameters are important for the feeding and reproduction of these fish. Considering that these fish are raised in lakes and dams, aquatic contamination with pyriproxyfen may hinder its breeding for human consumption, thus reducing fish farming efficiency. It is noteworthy that minor damages were observed in fish liver at a concentration of $0.4 \mathrm{mg} \mathrm{L}^{-1}$, representing potential harm to these fish, especially with prolonged exposures. However, O. niloticus exhibits greater resistance to pyriproxyfen than other fish previously reported, which may be useful for fish breeding in areas of mosquito infestations where this pesticide is widely applied directly into the water reservoirs. Pyriproxyfen may affect this fish's production and quality at higher concentrations than commonly used in water $(0.01 \mathrm{mg}$ $\left.\mathrm{L}^{-1}\right)$.

\section{ACKNOWLEDGMENTS}

We would like to thank the Conselho Nacional de Desenvolvimento Científico e Tecnológico (PPSUSCNPq) for the financial support in this study and the Coordenação de Aperfeiçoamento de Pessoal de Nível Superior (CAPES) for the scholarship awarded to FFS. We appreciate the suggestions of the reviewers to improve this manuscript. This work was supported by the Programa de Pesquisa para o SUS (PPSUS), Ministry of Health, Brazil; Federal University of Alagoas, Maceió, Alagoas, Brazil; Federal University of Pernambuco, Recife, Pernambuco, Brazil; Federal University of Paraíba, João Pessoa, Paraíba, Brazil.

\section{REFERENCES}

Abhijith, B.D., Ramesh, M. \& Poopal, R.K. 2016. Responses of metabolic and antioxidant enzymatic activities in gill, liver and plasma of Catla catla during methyl parathion exposure. Journal of Basic \& Applied Zoology, 77: 31-40. doi: 10.1016/j.jobaz. 2015.11.002

Brown, M.D., Thomas, I.D. \& Kayi, B.H. 1998. Acute toxicity of selected pesticides to the Pacific 392 blueeye, Pseudomugil signifer (Pisces). Journal of the American Mosquito Control Association, 393: 463466.

Caixeta, E.S., Silva, C.F., Santos, V.S.V., Campos-Junior E.O. \& Pereira, B.B. 2016. Ecotoxicological assessment of pyriproxyfen under environmentally realistic exposure conditions of integrated vector management for Aedes aegypti control in Brazil. Journal of Toxicology and Environmental Health, Part A, 79: 799-803. doi: 10.1080/15287394.2016.119 1400
Chaves, M.F., Moura, G.J., Silva, F.C.A., Baptista, J.S., Lapa-Neto, C.J.C., Wanderley-Teixeira, V. \& Teixeira, A.A.C. 2017. Influence of rainfall and temperature on the spermatogenesis of Leptodactylus macrosternum (Anura: Leptodactylidae). Zoologia, 34: 1-7. doi: 10.3897/zoología.34.e20782

Clasen, B., Loro, V.L., Murussi, C.R., Tiecher, T.L., Moraes, B. \& Zanella, R. 2018. Bioaccumulation and oxidative stress caused by pesticides in Cyprinus carpio reared in a rice-fish system. Science of the Total Environment, 626: 737-743. doi: 10.1016/j.scitotenv. 2018.01.154

Dzieciolowska, S., Larroque, A.L., Kranjec, L.A., Drapeau, P. \& Samarut, E. 2017. The larvicide pyriproxyfen blamed during the Zika virus outbreak does not cause microcephaly in zebrafish embryos. Scientific Reports, 7: 40067. doi: 10.1038/srep40067

Food and Agriculture Organization (FAO). 2010. Cultured aquatic species information programme. [http://www.fao.org/fishery/culturedspecies/Oreochro mis_niloticus/en]. Reviewed: July 13, 2019.

Furuya, W.M., Neves, P.R., Silva, L.C.R., Botaro, D., Hayashi, C. \& Sakaguti, E.S. 2004. Fitase na alimentação da Tilápia do Nilo (Oreochromis niloticus), durante o período de reversão de sexo. Acta Scientiarum. Animal Sciences, 3: 299-303. doi: 10.4025/actascianimsci.v26i3.1778

García de la Parra, L.M., Bautista-Covarrubias, J.C., Rivera-de la Rosa, N., Betancourt, L.M. \& Guilhermino, L. 2006. Effects of methamidophos on acetylcholinesterase activity, behavior, and feeding rate of the white shrimp (Litopenameus vannamei). Ecotoxicology and Environmental Safety, 65: 372380. doi:10.1016/j.ecoenv.2005.09.001

Glorieux, C., Zamocky, M., Sandoval, J.M., Verrax, J. \& Calderon, P.B. 2015. Regulation of catalase expression in healthy and cancerous cells. Free Radical Biology and Medicine, 87: 84-97. doi: 10.1016/j.freeradbiomed.2015.06.017

LaVerda, N.L., Goldsmith, D.F., Alavanja, M.C.R. \& Hunting, K.L. 2015. Pesticide exposures and body mass index (BMI) of pesticide applicators from the agricultural health study. Journal of Toxicology and Environmental Health, Part A, 78(20): 1255-1276. doi: 10.1080/15287394.2015.1074844

Legrand, E., Boulan-Gélecomte, C., Restoux, G., Trémolet, G., Duflot, A. \& Forget-Leray, J. 2017. Individual and mixture acute toxicity of model pesticides chlordecone and pyriproxyfen in the estuarine copepod Eurytemora affinis. Environmental Science and Pollution Research, 24: 59-76. doi: 10.1007/s11356-016-8294-5

Maharajan, K., Muthulakshmi, S., Nataraj, B., Ramesha, M. \& Kadirvelu, K. 2018. Toxicity assessment of pyriproxyfen in vertebrate model zebrafish embryos 
(Danio rerio): a multi biomarker study. Aquatic Toxicology, 196: 132-145. doi: 10.1016/j.aquatox. 2018.01.010

Maoz, D., Ward, T., Samuel, M., Müller, P., RungeRanzinger, S., Toledo, J., Boyce, R., Velayudhan, R. \& Horstick, O. 2017. Community effectiveness of pyriproxyfen as a dengue vector control method: a systematic review. Plos Neglected Tropical Diseases, 11(7): e0005651. doi: 10.1371/journal.pntd.0005651

Marcondes, C.B. \& Ximenes, M.F. 2016. Zika virus in Brazil and the danger of infestation by Aedes (Stegomyia) mosquitoes. Revista da Sociedade Brasileira de Medicina Tropical, 49: 4-10. doi: 10.1590/0037-8682-0220-2015

Meijering, E., Dzyubachyk, O. \& Smal, I. 2012. Methods for cell and particle tracking. Methods Enzymology, 504: 183-200. doi: 10.1016/B978-0-12-3918574.00009-4

Meng, S.L., Chen, J.Z., Xu, P., Qu, J.H., Fan, L.M., Song, C. \& Qiu, L.P. 2014. Hepatic antioxidant enzymes SOD and CAT of Nile Tilapia (Oreochromis niloticus) in response to pesticide methomyl and recovery pattern. Bulletin of Environmental Contamination and Toxicology, 92: 388-392. doi: 10.1007/s00128-0141232-7

Meurer, F., Bombardelli, R.A., Hayashi, C. \& Fornari, D.C. 2005. Grau de moagem dos alimentos em rações para a Tilápia do Nilo (Oreochromis niloticus) durante o período de reversão sexual. Acta Scientiarum. Animal Sciences, 1: 81-85.

Moraes, B.S., Loro, V.L., Glusczak, L., Pretto, A., Menezes, C., Marchezan, E. \& de Oliveira-Machado, S. 2007. Effects of four rice herbicides on some metabolic and toxicology parameters of teleost fish (Leporinus obtusidens). Chemosphere, 68: 1597-601. doi: 10.1016/j.chemosphere.2007.03.006

Ohba, S-Y., Ohashi, K., Pujiyati, E., Higa, Y., Kawada, H., Mito, N. \& Takagi, M. 2013. The effect of pyriproxyfen as a "population growth regulator" against Aedes albopictus under semi-field conditions. Plos One, 7: 1-10. doi: 10.1371/journal.pone.0067045

Ose, K., Miyamoto, M., Fujisawa, T. \& Katagi, T. 2017. Bioconcentration and metabolism of pyriproxyfen in tadpoles of African clawed frogs, Xenopus laevis. Journal of Agriculture and Food Chemistry, 65: 99809986. doi: 10.1021/acs.jafc.7b04184

Peterson, E.K., Buchwalter, D.B., Kerby, J.L., Lefauve, M.K., Varian-Ramos, C.W. \& Swaddle, J.P. 2017. Integrative behavioral ecotoxicology: bringing together fields to establish new insight to behavioral ecology, toxicology, and conservation. Current Zoology, 2: 185-194. doi: 10.1093/cz/zox010

Prabu, E., Rajagopalsamy, C.B.T., Ahilan, B., Jeevagan, I.J. \& Renuhadevi, M. 2019. Tilapia - an excellent candidate species for world aquaculture: a review.
Annual Research and Review in Biology, 31(3): 1-14. doi: 10.9734/arrb/2019/v31i330052

Renick, V.C., Weinersmith, K., Vidal-Dorsch, D.E. \& Anderson, T.W. 2016. Effects of a pesticide and a parasite on neurological, endocrine, and behavioral responses of an estuarine fish. Aquatic Toxicology, 170: 335-343. doi: 10.1016/j.aquatox.2015.09.010

Santos, V.S.V., Caixeta, E.S., Campos Jr., E.O. \& Pereira, B.B. 2017. Ecotoxicological effects of larvicide used in the control of Aedes aegypti on non-target organisms: redefining the use of pyriproxyfen. Journal of Toxicology and Environmental Health, Part A, 80: 155-160. doi: 10.1080/15287394.2016.1266721

Silva, J.M., Santos, F.L.B., Tenório, H.A., Pereira, H. J.V., Costa, J.G., Santana, A.E.G., Machado, S.S. \& Abreu, F.C. 2015. In vivo and in vitro inhibition of cholinesterase activity in Colossoma macropomum (tambaqui) fingerlings by the herbicide trifluralin. Ecotoxicology and Environmental Contamination, 1: 23-30. doi: 10.5132/eec.2015.01.04

Sullivan, J.J. \& Goh, K.S. 2008. Environmental fate and properties of pyriproxyfen. Journal of Pesticide Science, 4: 339-350.

Tenorio, B.M., Silva-Filho, E., Neiva, G.S.M., Silva Jr., V.A., Tenorio, F.C.A.M., Silva, T.J., Soares, E.C. \& Nogueira, R.A. 2017. Can fractal methods applied to video tracking detect the effects of deltamethrin pesticide or mercury on the locomotion behavior of shrimps. Ecotoxicology and Environmental Safety, 142: 243-249. doi: 10.1016/j.ecoenv.2017.03.051

Truong, L., Gonnerman, G., Simonich, M.T. \& Tanguay, R.L. 2016. Assessment of the developmental and neurotoxicity of the mosquito control larvicide, pyriproxyfen, using embryonic zebrafish. Environmental Pollution, 218: 1089-1093. doi: 10.1016/j. envpol.2016.08.061

Ural, M.Ş. 2013. Chlorpyrifos-induced changes in oxidant/antioxidant status and haematological parameters of Cyprinus carpio: ameliorative effect of lycopene. Chemosphere, 7: 2059-2064. doi: 10.1016/ j.chemosphere.2012.12.006

Vicentini, C.A., Franceschini-Vicentini, I.B., Bombonato, M.T.S., Bertolucci, B., Lima, S.G. \& Santos, A.S. 2005. Morphological study of the liver in the teleost Oreochromis niloticus. International Journal of Morphology, 3: 211-216. doi: 10.4067/S0717-95022 005000300003

Vieira, C.A.S.C., Vieira, J.S., Bastos, M.S., Zancanela, V., Barbosa, L.T., Gasparino, E. \& Del Vesco, A.P. 2018. Expression of genes related to antioxidant activity in Nile tilapia kept under salinity stress and fed diets containing different levels of vitamin C. Journal of Toxicology and Environmental Health, Part A, 81(13): 20-30. doi: 10.1080/15287394.2017.1401968 
World Health Organization (WHO). 2006. World Health Organization specifications and evaluations for public health pesticides pyriproxyfen. FAO/WHO evaluation report, 715/2015, $26 \mathrm{pp}$.

Received: March 11, 2020; Accepted: July 23, 2020
Zhu, X.-W. \& Chen, J.-Y. 2016. Mixtox: an R package for mixture toxicity assessment. The R Journal, 8: 421433. 